\title{
UMA EPISTEMOLOGIA VERDADEIRAMENTE ENGAJADA ${ }^{1}$ \\ A TRULY ENGAGED EPISTEMOLOGY
}

Anselmo Peres Alós
ORCID 0000-0003-2062-2096

Universidade Federal de Santa Maria Santa Maria, RS, Brasil

Professora aposentada de Literatura Norte-Americana na Universidade Federal do Rio Grande do Sul (UFRGS), Rita Terezinha Schmidt é uma das mais importantes vozes da crítica literária feminista brasileira. Autora de inúmeros artigos e capítulos de livros publicados no Brasil e no exterior, Descentramentos/convergências: ensaios de crítica feminista é o primeiro livro individual da autora. Trata-se de uma coletânea de trabalhos publicados ao longo de sua carreira (tais como capítulos em livros coletivos já esgotados ou anais de eventos acadêmicos de circulação restrita ao grande público) que, pela primeira vez, são disponibilizados de forma reunida a um público leitor mais amplo e não necessariamente acadêmico.

A apresentação do livro é assinada por Susana Bornéo Funck, professora titular aposentada de Literaturas de Língua Inglesa da Universidade Federal de Santa Catarina (UFSC). É de Susana a frase que tomo de empréstimo para usar como título nessa resenha. Vale a pena retomá-la, em seu devido contexto, de modo a dar uma primeira avaliação da importância do trabalho de Rita Terezinha Schmidt:

[Os ensaios de Rita Terezinha Schmidt] têm o grande mérito de trazer a crítica literária feminista para o debate maior da historiografia literária, fazendo dela instrumento desestabilizador de saberes cristalizados por meio de uma epistemologia verdadeiramente engajada. As análises apresentadas desmentem a generalizada crença em uma crítica feminista importada, sem relação com uma consciência nacional. Desmentem, da mesma forma, que a ideologia seja uma prerrogativa de grupos marginais e de minorias (FUNCK, 2017, p. 14).

1 Resenha de: SCHMIDT, Rita Terezinha. Descentramentos/convergências: ensaios de crítica feminista. Porto Alegre: Editora da UFRGS, 2017. 448p. 
Não há exageros nas palavras de Susana B. Funck. Os ensaios de Rita Schmidt reunidos em Descentramentos/convergências: ensaios de crítica feminista lançam novas luzes na compreensão da tradição literária brasileira, bem como no próprio entendimento do fenômeno literário no contexto mais amplo da cultura, coma a própria autora explicita já no início do livro. Para ela, a crítica literária feminista, entendida como procedimento epistemológico, tem como objetivo "descentrar o que sempre esteve no centro para descobrir o que foi encoberto, marginalizado ou silenciado para poder divisar, na diferença, novas convergências" (SCHMIDT, 2017, p. 17). Vivemos tempos sombrios, nos quais se reencenam as resistências de meados dos anos 1980, quando o recém-criado Grupo de Trabalho "A Mulher na Literatura" (sob os auspícios da Associação Nacional de Pós-Graduaçáo e Pesquisa em Linguística e Literatura - ANPOLL) precisava insistentemente demarcar seu espaço e defender o valor da pesquisa de viés feminista. Cabe lembrar que ainda persiste, nos Programas de Pós-Graduação em Letras no Brasil, "uma recusa em conceber o texto literário para além de sua dimensão estética [...], como se a forma estética pudesse ser depurada de sua política" (SCHMIDT, 2017, p. 23).

Uma das primeiras questóes fundamentais na articulação de uma prática crítica feminista no campo dos estudos literários é o questionamento do entendimento limitado de literatura apenas como objeto estético. No mesmo eixo de outras vertentes críticas, tais como os estudos culturais, a crítica pós-colonial e o novo historicismo, uma das principais estratégias é a de questionar a suposta estabilidade da definição de termos substantivados e essencializados, tais como "a literatura", "o canônico" e "o estético":

A pressuposição de que um texto é literatura e outro não é decorre de um sentido específico do literário que foi historicamente construído e transmitido pela socialização da leitura efetivada em processos de formação e contato com um elenco de obras definidas em termos de um valor inalterável, tal como são consideradas as obras canônicas (SCHMIDT, 2017, p. 26 - destaque meu).

Sempre que se remonta ao valor estético como recurso para a definição da literatura, o que se ergue é uma definição de caráter normativo. É evidente o fato de que os julgamentos de valor dessa natureza (normativa) náo estáo baseadas no objeto literário em si: "um julgamento de valor nada diz sobre o objeto, mas sim algo sobre a relação sujeito/objeto e, nesse sentido, valor não se configura como um conceito absoluto, mas relativo" (SCHMIDT, 2017, p. 29). Questionar e problematizar o entendimento dessas categorias fundamentais no campo dos estudos literários - como a própria categoria do literário: seu alcance, sua validade e suas limitaçôes - transforma a crítica feminista em 
uma poderosa ferramenta de revisão epistemológica dos próprios princípios fundamentais que regem os limites disciplinares dos estudos literários. Por mais evidente que pareça, nunca é demais lembrar - em especial àqueles críticos que fazem questão de esquecer - o caráter histórico e socialmente situado de todo e qualquer dispositivo de produção de conhecimento:

O conhecimento humano, como tudo o que é humano, é condicionado historicamente e construído socialmente, o que implica dizer que os interesses dos que produzem conhecimento - pesquisadores, comunidades científicas, pensadores da cultura - determinam a forma do conhecimento produzido (SCHMIDT, 2017, p. 26).

Se todo e qualquer dispositivo de produção de conhecimento é contextual e historicamente situado, o mesmo pode ser dito do entendimento dado à categoria "literatura" no interior da história, da teoria e da crítica literárias (WELLEK e WARREN, 1999). O que separa o texto literário avaliado como "bom" do texto literário avaliado como "ruim"? A própria definição de "texto literário" que permite essa qualificação já é, por si só, uma construção histórica de funcionamento deliberadamente político. As relaçôes entre saber e poder não mais podem ser ignoradas, pelo menos não depois do advento da filosofia de Michel Foucault (2007), que tornou evidente as relaçóes entre saber e poder entranhadas no paradigma patriarcal da cultura letrada e na própria construção dos diferentes domínios disciplinares: "o argumento de que um texto é menor ou fraco porque náo se enquadra nos protocolos de valor, historicamente subscritos e aceitos, já é uma posição escancaradamente política. O que a crítica literária tem feito, no campo dos estudos literários, é politizar o que sempre foi politico" (SCHMIDT, 2017, p. 31 - grifo meu).

Náo podemos esquecer - como nos alerta Schmidt - da absoluta necessidade de inserirmo-nos como sujeitos pensantes, de e na narrativa da nação, isto é, na cultura, na língua e na história, uma vez que "a literatura [...] exerce profundas influências sobre a maneira como os indivíduos interpretam e mitologizam suas realidades e a maneira como dispóem de suas experiências" (SCHMIDT, 2017, p. 68). Nesse sentido, repensar o continuum da história literária brasileira é repensar a própria identidade brasileira, bem como os arranjos de organização social da nação. Destaque-se que essa abordagem é uma das principais preocupaçóes da crítica literária feminista, que se preocupa, simultaneamente, em reavaliar o lugar da mulher como produtora de textos ao longo da história, bem como o seu lugar como leitora de textos e, finalmente, quais as modalidades de representação das mulheres no interior da economia poética e narrativa dos próprios textos. 
É escusado lembrar que, tanto ao longo da história da literatura ocidental quanto ao longo da história literária brasileira, a produção dos textos literários e as representaçóes de mulheres que neles figuram recaem sintomaticamente - nos chamados homens de letras. Como destaca a autora de Descentramentos/convergências, "toda atividade de interpretação mantém profundas e complexas relaçóes com a política, com as estruturas de poder e valor social pela qual organizamos e damos sentido à vida em sociedade, pelo simples fato de lidar com significados e valores" (SCHMIDT, 2017, p. 76).

Os vínculos entre política e interpretação são muito claros para a crítica literária feminista, tanto que não raro, fala-se em políticas da interpretação, termo bastante recorrente também na crítica pós-colonial e na crítica cultural afiliada ao materialismo histórico. Esses vínculos são bastante evidentes para Schmidt, que defende a ideia de que "interpretar de uma forma ou de outra é uma questão de escolha interessada, e o fato desses interesses serem muitas vezes inconscientes, com resultados não previsíveis, não os torna menos políticos" (SCHMIDT, 2017, p. 77). Essa é a resposta da autora a possíveis rechaços ao seu trabalho sob a acusação de que a crítica literária feminista é interessada. Ora, e qual vertente crítica não é interessada? Indo mais além, é possível a realização de alguma atividade cognitiva, com vistas à produçáo de conhecimento, sem que se mobilize algum tipo de interesse? Como esclarece a autora, esse questionamento das políticas da neutralidade e da objetividade epistêmicas estão nas bases do pensamento teórico feminista: "esse é o ponto de partida para a problematização feminista da produção de conhecimento sobre as mulheres: como, onde, por quem e para quem o conhecimento é produzido? E o que conta como conhecimento?” (SCHMIDT, 2017, p. 79).

É a partir desse conjunto de pressupostos que a autora revisita a tradição literária oitocentista brasileira, lendo romances de autoria feminina que foram sistematicamente ignorados pela crítica literária consagrada, de modo a realocar esses textos na séria histórica da literatura brasileira ao mesmo tempo em que desloca e redimensiona essa série histórica. Ao longo das 448 páginas do volume, a autora analisa o lugar e a importância de romances tais como os de Júlia Lopes de Almeida ${ }^{2}$, Maria Benedita Bormann ${ }^{3}$ e Andradina de Oliveira ${ }^{4}$, ao mesmo tempo em que relê autores consagrados da literatura brasileira (tais como Clarice Lispector e Machado de Assis) a partir das lentes críticas do feminismo. Esse gesto leva a pesquisadora, inevitavelmente, a

2 Cf. ALMEIDA, Júlia Lopes de. A falência. Florianópolis: Editora Mulheres, 2003.

3 Cf. Maria Benedita Bormann. Lésbia (a primeira edição é de 1890). A edição mais recente conta com atualizaçăo do texto e introdução assinadas por Norma Telles (Florianópolis: Editora Mulheres, 1998).

4 Cf. Andradina de Oliveira. O perdão (Porto Alegre: Livraria Editora Americana, 1910). Há uma segunda edição disponível (Florianópolis: Editora Mulheres, 2010). 
refletir sobre as possibilidades e limites, no campo dos estudos literários, da categoria de cânone:

Revisitar velhos territórios olhando para o cânone [...] é reinterpretar o passado à luz de novas categorias analíticas que possam responder às questôes que dirigimos do presente a esse passado, é repensar a própria noção de cultura brasileira em sua identidade múltipla e diversa, é reconstruir a literatura brasileira integrando a presença, a representatividade e a diferença das escritoras brasileiras (SCHMIDT, 2017, p. 164).

Ao revisitar a tradição literária brasileira com vistas a nela encontrar o devido espaço para as escritoras brasileiras do século XIX, torna-se inevitável repensar e problematizar a noção de cânone literário. Se é verdade que "todo cânone é uma forma institucionalizada através da qual uma cultura específica define e determina o que vem a ser sua literatura representativa, isto é, os textos de referência que recortaram a singularidade discursiva e representacional daquela cultura" (SCHMIDT, 2017, p. 89), também é verdade que a construção de um cânone, ao longo do tempo, é o resultado do trabalho de críticos e historiadores da literatura, e que esse trabalho está a serviço de alguns interesses, e não de outros. Dito de outra maneira, é possível afirmar, tal como a autora de Descentramentos/convergências, "[que] a constituição de um cânone é, na base, uma decorrência de poder de discursos críticos e das instituiçóes que o abrigam" (SCHMIDT, 2017, p. 157). Esse poder que se encontra nos fundamentos dos discursos críticos e instituiçóes que salvaguardam o cânone, por sua vez, não podem ser avaliados meramente em função de elementos formais (o rigor estético, a construção estrutural de um dado texto); mais do que um compromisso com a forma, esse poder define a que interesse servem os textos que constituem o cânone literário: "quem escreve o quê para quem, o que faz um determinado texto, que códigos se utilizam, com que fim e a que interesses servem, são perguntas que ultrapassam de longe os limites de uma avaliação puramente formal dos textos" (SCHMIDT, 2017, p. 174).

Que tipos de saber são produzidos pelas formas mais convencionais de crítica e de historiografia literária? Esse conhecimento efetivamente faz jus ao lugar que as mulheres ocupam nas searas literárias como objetos de representação (personagens), como sujeitos da representação (escritoras), ou ainda, como agentes da interpretação (isto é, como leitoras, ora leigas, ora acadêmicas)? Essas são perguntas que ecoam entre as páginas do livro de Rita Terezinha Schmidt, e que a autora, a cada capítulo, tenta reiteradamente responder: 
Revisitar a nossa identidade literária e cultural, escrevendo o gênero, a raça e a classe social na leitura e na revisitação da historiografia literária, implica conjugar as nossas capacidades afetivas, sociais e intelectuais na primazia a ser dada à sociabilidade e à responsabilidade no nosso encontro com o outro (SCHMIDT, 2017, p. 232).

Em poucas palavras, pode-se dizer que a contribuição fundamental de Descentramentos/convergências para os estudos de literatura brasileira é a de questionar a ética da representação literária tal e qual se apresenta no discurso canônico da historiografia literária brasileira.

\section{Referências}

ALMEIDA, Júlia Lopes de. A falência. Florianópolis: Editora Mulheres, 2003.

BORMANN, Maria Benedita. Lésbia. Atualização do texto e introdução por Norma Telles. Florianópolis: Editora Mulheres, 1998.

FOUCAULT, Michel. Microfísica do poder. 24a. ed. São Paulo: Graal, 2007.

FUNCK, Susana Bornéo. "Apresentação". In: SCHMIDT, Rita Terezinha. Descentramentos/convergências: ensaios de crítica feminista. Porto Alegre: Editora da UFRGS, 2017, p. 11-16.

OLIVEIRA, Andradina de. O perdão. Porto Alegre: Livraria Editora Americana, 1910.

OLIVEIRA, Andradina de. O perdão. 2a. ed. Introdução de Rita Terezinha Schmidt. Florianópolis: Editora Mulheres, 2010.

WELLEK, René e WARREN, Austin. Teoria da literatura. 5a. ed. São Paulo: Pioneira, 1999.

Anselmo Peres Alós possui Graduação em Letras (2002) e Doutorado em Letras (2007) pela Universidade Federal do Rio Grande do Sul (UFRGS). É Professor Associado I na Universidade Federal de Santa Maria (UFSM), na cidade de Santa Maria/RS. Foi Professor-Visitante na Universidade Federal da Integração Latino-Americana (UNILA), Professor-Leitor junto ao Instituto Superior de Ciência e Tecnologia de Moçambique (ISCTEM), e Professor-Colaborador do Centro Cultural Brasil-Moçambique (CCBM) e do Instituto Superior de Comunicação e Imagem de Moçambique (ISCIM), em Maputo, no período de 2009 a 2011. É Líder do Grupo de Pesquisa Trânsitos teóricos e deslocamentos epistêmicos: feminismos, estudos de gênero e teoria queer', cadastrado junto ao Diretório dos Grupos de Pesquisa do Brasil do CNPq. Autor de A letra, o corpo e o desejo: masculinidades subversivas no romance latino-americano (2013) e de Leituras a contrapelo da narrativa brasileira: redes intertextuais de gênero, raça e sexualidade (2017). Organizador dos livros Poéticas da masculinidade em ruinas: o amor em tempos de AIDS (2017) e Configuraçôes do imaginário cinematográfico na contemporaneidade (com Renata Farias de Felippe e Andrea do Roccio Souto, 2017).

E-mail: anselmoperesalos@gmail.com 